Coker et al., Afr J Tradit Complement Altern Med., (2018) 15 (3): 64-71

https://doi.org/10.21010/ajtcam.v15i3.8

\title{
EVALUATION OF THE WOUND HEALING POTENTIAL OF OINTMENT PREPARATION OF ETHYL-ACETATE EXTRACT OF MORINGA OLEIFERA (LAM) IN RATS
}

\author{
Morenike Coker $^{1}$, Grace Adejo ${ }^{1}$, Benjamin Emikpe ${ }^{2,3^{*}}$, Victor Oyebanji ${ }^{2}$ \\ ${ }^{1}$ Department of Pharmaceutical Microbiology, Faculty of Pharmacy, University of Ibadan, Nigeria. \\ ${ }^{2}$ Department of Veterinary Pathology Faculty of Veterinary Medicine, University of Ibadan, Nigeria. \\ ${ }^{3}$ Department of Pathobiology, School of Veterinary Medicine, Kwame Nkrumah University of Science and \\ Technology, Kumasi, Ghana.
}

*Corresponding Author E-mail: banabis2001@yahoo.com

\begin{tabular}{|l|}
\hline \multicolumn{1}{|c|}{ Article History } \\
Received: Feb. 15, 2017 \\
Revised Received: July. 15, 2017 \\
Accepted: Aug. 07, 2017 \\
Published Online: May. 31, 2018 \\
\hline
\end{tabular}

Abstract

Background: This study examined the in vitro antibacterial property of extracts of Moringa oleifera and the effect of different concentrations of the ethyl-acetate extract on cutaneous wound using an ointment delivery base. The aim of the study was to screen the extracts with best antibacterial property and evaluate effectiveness of different concentrations of the best extract when delivery is modified to ensure prolonged contact and reduced frequency of administration using an ointment base delivery vehicle.

Materials and Methods: Dried and pulverized leaves of Moringa oleifera were screened for secondary metabolites. Successive gradient extraction was carried out using n-hexane, ethyl acetate and methanol. Leaf extracts were screened against clinical wound isolates of Staphylococcus aureus, Escherichia coli, Pseudomonas aeruginosa, Klebsiella pneumoniae and Proteus mirabilis using agar cup diffusion technique. The ethyl acetate extract was investigated for its healing efficiency on excision wound model in rats. The study made use of wistar rats (150-180 kg), randomized into Gentamicin, M. oleifera ointment (5\% and 3.25\%), and ointment base treatment groups. Treatments were applied topically on days 0,7 and 14 . The percentage wound closure rate was measured and histopathology of the healed wounds carried out.

Results: In vitro antimicrobial screening showed that ethyl-acetate extract was effective against the test isolates. Topical application of ointment with $3.25 \%$ of the plant extract resulted in faster wound closure rate, rapid epithelization, resolution of granulation tissue, and remodeling at histology.

Conclusion: This may be due to less interference by components of M. oleifera which appear to retard wound healing at higher concentrations. Therefore, M. oleifera $3.25 \%$ ointment preparation is recommended topically for wound healing.

Keywords: Antimicrobial, ethyl acetate, Moringa oleifera, wound healing, ointment.

\section{Introduction}

The skin is one of the predominant organs in the body serving as a barrier to agents including microorganisms. A discontinuity in the skin due to injury can weaken its defense mechanisms, thereby making the surrounding more favorable for invasion and proliferation of bacteria (Bowler et al 2001; Enoch and Leaper, 2005 Demidova-Rice et al 2012). Wounds are injuries arising from a breach or an opening in the skin, causing a disturbance in the cellular and functional anatomy of the skin (Strodtbeck, 2001). Wound healing is a biological process whereby damaged tissues are being repaired and restored; it takes place as a result of response of tissues and cells to injury and in the process, fibroblast, endothelial cells, and macrophages are activated to aid the wound healing process (Tam et al., 2011). The initial stage involves an acute inflammatory process, collagen synthesis and formation of other extracellular macromolecules to close up the wound area. It requires sufficient supply of blood to the impaired tissue and a continuous cell-cell and cell-matrix interactions which allows the wound healing process to progress in four overlapping phases; Hemostasis, inflammation, proliferation and remodeling, (Sumitra et al., 2005). The process of wound healing may be hampered by microbial infection or the presence of free radicals, which can cause damage to the cells surrounding the wound (Reddy et al, 2007). 
Wound infections are most common in developing countries because of poor hygienic conditions while wound care has become a problem due to increase in resistance of microorganisms to existing antibiotics, high cost of therapy and undesirable side effects during prolonged treatments with antibiotics (Filius and Gyssens 2002; Pattanayak and Sunita, 2008; Pîrvănescu et al 2014). This has led to a search for newer and better alternatives with antioxidant properties that can aid wound healing in a natural way. Medicinal plants have long been used in traditional medicine for the treatment of various ailments of the skin (Kumar et al., 2007) and are known to contain bioactive compounds (Okigbo et al., 2008), that possess antimicrobial properties (Srinivasan et al., 2001).

Nigeria has a wide array of indigenous plants, which are used in herbal medicine to cure diseases and heal injuries (Okwu and Josiah 2006). One of such plants is the Moringa plant (Moringa oleifera Lam). It grows rapidly in most regions and climatic conditions of Nigeria where its known locally as 'Okwe oyibo' in Igbo, 'Gawara' or 'Habiwal' in Hausa and 'Adagba maloye' or 'Ewe Igbale' in Yoruba (Anwar et al., 2007). Most part of this plant such as the root, bark, gum, leaf, fruit (pods) flowers, seed and seed oil are being employed for the treatment of different ailments in folk medicine (Fahey, 2005; Adline and Devi, 2014).

The Moringa plant has been found to contain a rich combination of zeatin, quercetin, $\beta$-sitosterol, caffeoylquinic acid and kaempferol. Vitamins, carotenoids, polyphenol, phenolic acids, flavonoids, alkaloids, glucosinolates, isothiocyanates, tannins, saponins, oxalates and phytates have also been found in this plant (Anwar et al., 2007). Medicinal application reported for M. oleifera includes its use as an antiseptic, in treating rheumatism, venomous bites, and other activities such as antimicrobial, anti-spasmodic, anti-ulcer, hepatoprotective, antioxidant, anti-tumour, anti-inflammatory, anti-diabetic, anti-cancer, hypolipidemic, infertility and anti-hypertensive properties (Dangi et al., 2002). Traditionally, Moringa oleifera has been used in the treatment of infected wounds and sore eyes for which the "leaf-paste" is applied on the infected part. The leaves are normally applied as poultice to sores and wounds by traditional healers and have been shown to be effective (Rathi et al., 2006). Phytosterols and phenolic compounds present in the ethyl-acetate extract of $M$. oleifera was reported to promote wound healing activity in resutured, incision, excision, and dead space wound models in rats (Hukkeri et al., 2006).

Thus, the antimicrobial potentials of different extracts of $M$. oleifera were studied against some predominant bacteria colonizing wounds and the most effective of the extract at different concentrations in an ointment base was used to evaluate the wound healing potential in rats.

\section{Materials and Methods \\ Plant collection, preparation and phytochemical screening}

Fresh leaves of M. oleifera were collected in Iwo, Nigeria and authenticated at the Forestry Research Institute of Nigeria, Ibadan with voucher number FHI 111095. The leaves were oven-dried at $65{ }^{0} \mathrm{C}$ to constant weight and pulverized with an electrical grinder. The powdered plant part was screened for secondary metabolites using standard procedures (Sofowora, 1993; Trease and Evans, 2002).

\section{Plant extraction}

Successive solvent extraction was carried out with the soxhlet apparatus using solvents of increasing polarity; $\mathrm{n}$-hexane, ethyl acetate and methanol. The extracts were concentrated under reduced pressure using a rotary evaporator. The dried extracts were stored at $4{ }^{0} \mathrm{C}$ in a refrigerator.

\section{Microorganisms}

The bacteria used for the study were pure cultures of clinical wound isolates obtained from the Department of Medical Microbiology, University College Hospital, Ibadan, Nigeria. The microorganisms were Pseudomonas aeruginosa, Staphylococcus aureus, Klebsiella pneumoniae, Escherichia coli and Proteus mirabilis. All bacterial isolates were maintained on nutrient agar slants at temperature of $4^{\circ} \mathrm{C}$.

\section{Antibacterial bioassay}

The antibacterial activity of the extracts of $M$. oleifera was determined by agar-cup diffusion method in which $0.1 \mathrm{~mL}$ of $18 \mathrm{~h}$ culture (equivalent to $1.0 \times 10^{6} \mathrm{cfu} / \mathrm{mL}$ ) was used to seed Mueller Hinton agar plates. Equidistant wells were bored into the seeded agar with a sterile cork borer $(8 \mathrm{~mm}$ diameter) and each well was filled with graded concentrations of the reconstituted extract. The plates were incubated for $24 \mathrm{~h}$ at $37{ }^{0} \mathrm{C}$ and the diameter of zone of growth inhibition was measured and compared with the zones produced by Gentamicin, the standard antibiotic used as control.

\section{Extracts and standards used}

Two types of ointment formulations were prepared with ethyl acetate (EA) leaf extract as described by Arulselvan et al (2016). The 3.25\% (w/w) ointment where $0.65 \mathrm{~g}$ of extract was incorporated into $20 \mathrm{~g}$ of simple ointment base B.P. and 5\% (w/w) ointment (1 g of extract in $20 \mathrm{~g}$ simple ointment base B.P). 
Simple ointment base B.P. served as the negative control while Gentamicin $(10 \mu \mathrm{g} / \mathrm{mL})$ was used as the standard drug control for comparing the wound healing potential of the extract in different animal models.

\section{Experimental Animals}

An ethical approval was obtained from the Animal Care Use and Research Committee (ACUREC), University of Ibadan, Nigeria before the commencement of the experiment.

Sixteen healthy Wistar female albino rats (150-180 kg) were divided into four groups of four animals each and were housed individually in plastic cages. Animals were fed with standard pellet diet and water ad libitum. The rats were used after acclimatization to the laboratory environment for a 7 day period.

For the experiments, the rats were anaesthetized with ketamine hydrochloride $(0.3 \mathrm{~mL})$ and xylazine $(0.1 \mathrm{~mL})$. Excision wound was inflicted on the rats as described by Murthy et al (2013) where about $500 \mathrm{~mm}^{2}$ full thickness of skin was cut away from pre-determined area on the rats. The ethyl acetate extract ointments, simple ointment base and Gentamicin ointment were administered topically on the wound sites till the wounds were completely healed. Wound healing potential was determined by the rate of wound contraction and wound closure time. Wound area was measured as described by Schultz et al (2005) which is done by tracing the wound margin on a millimeter scale transparent graph paper on the day of wound creation and subsequently every alternate day until healing was completed. The degree of wound healing was calculated. Wound contraction was calculated as percentage reduction in wound area.

Percentage wound contraction $=1-($ Area of studied day/Area of initial day) $x 100$ (Estevão et al 2017)

Sampled rats in each group were euthanized while healed wound sites were excised, fixed in $10 \%$ formalin and sectioned for histology examination.

\section{Statistical analysis}

Results were expressed as mean \pm standard deviation. Two-way analysis of variance (ANOVA) was used to analyse the difference in the mean values of animals treated with the extract cream and control antibiotics.

\section{Results}

Phytochemical analysis showed the presence of flavonoids, saponins, phlobatannins, alkaloids, anthraquinones, steroids and resins. The in vitro antimicrobial screening of ethyl acetate extract is shown in Table 1 while that of the three extracts is presented in Table 2 which showed ethyl-acetate extract to be the only active extract against the wound pathogens. The standard drug (gentamicin) used for the in vitro screening was not effective on Staphylococcus aureus but the ethyl-acetate extract showed appreciable antimicrobial effect against all the wound isolates used, indicating its broad spectrum of activity (Figure I). The ethyl-acetate extract being the only active extract in in vitro antimicrobial assay at a concentration of $12.5 \mathrm{mg} / \mathrm{mL}$ was used in formulating the ointment for the in vivo studies in rats.

Animals in groups A, B and C showed increase in percentage wound contraction and significant decrease in epithelization period (Figure II; Table 3) as compared to group D (ointment base). Group C (3.25\% M. oleifera ointment) showed the best result with $100 \%$ percentage wound closure on day 15 .

Histology presented in Figure 3 below showed rate of epithelization in each agroup. Group A-C presents with complete epitheliazation (although thin in group A: gentamicin), absence of neutrophils, or any other inflammatory cells, resolution of granulation tissue followed by re-organization of dermal-epidermal structures evidenced by hair follicles. Group D: control also presents with healing effort evidenced by epitheliazation but retains presence of granulation tissue in the dermal layer signifying tissue re-organization at a slower pace compared to the treatment or positive control (gentamicin) groups.

Table 1: Antimicrobial screening of ethyl acetate leaf extract $(\mathrm{mg} / \mathrm{mL})$

\begin{tabular}{lcccccc}
\hline \multicolumn{1}{c}{ Microorganisms } & ZONES OF INHIBITION OF EXTRACTS (mm) & & \\
& 200 & 100 & 50 & 12.5 & 6.125 & Gentamycin \\
& & & & & & NZI \\
\hline Pseudomonas aeruginosa & $36 \pm 1.5$ & $25 \pm 0.6$ & $18 \pm 1.2$ & $15 \pm 1.0$ & $20 \pm 0.0$ \\
Staphylococcus aureus & $28 \pm 1.5$ & $21 \pm 1.2$ & $14 \pm 1.0$ & $11 \pm 0.6$ & NZI & NZI \\
Klebsiella pneumoniae & $37 \pm 0.6$ & $22 \pm 1.1$ & $14 \pm 0.0$ & NZI & NZI & $14 \pm 1.0$ \\
Escherichia coli & $30 \pm 1.0$ & $21 \pm 1.0$ & $15 \pm 1.2$ & $12 \pm 0.6$ & NZI & $17 \pm 0.6$ \\
Proteus mirabilis & $36 \pm 0.6$ & $26 \pm 0.0$ & $20 \pm 0.6$ & $16 \pm 0.0$ & NZI & $24 \pm 1.0$ \\
\hline
\end{tabular}

Key: NZI: No zone of inhibition 
Table 2: Table 2: Antimicrobial screening of all the extracts $(12.5 \mathrm{mg} / \mathrm{mL})$

ZONES OF INHIBITION OF EXTRACTS (mm)

Microorganisms Hexane Ethyl acetate Methanol Gentamicin $(10 \mu \mathrm{g} / \mathrm{mL})$

\begin{tabular}{lcccc}
\hline Pseudomonas aeruginosa & NZI & $15 \pm 1.0$ & NZI & $20 \pm 0.0$ \\
Staphylococcus aureus & NZI & $11 \pm 0.6$ & NZI & NZI \\
Klebsiella pneumonia & NZI & NZI & NZI & $14 \pm 1.0$ \\
Escherichia coli & NZI & $12 \pm 0.6$ & NZI & $17 \pm 0.6$ \\
Proteus mirabilis & NZI & $16 \pm 0.0$ & & $24 \pm 1.0$ \\
\hline
\end{tabular}

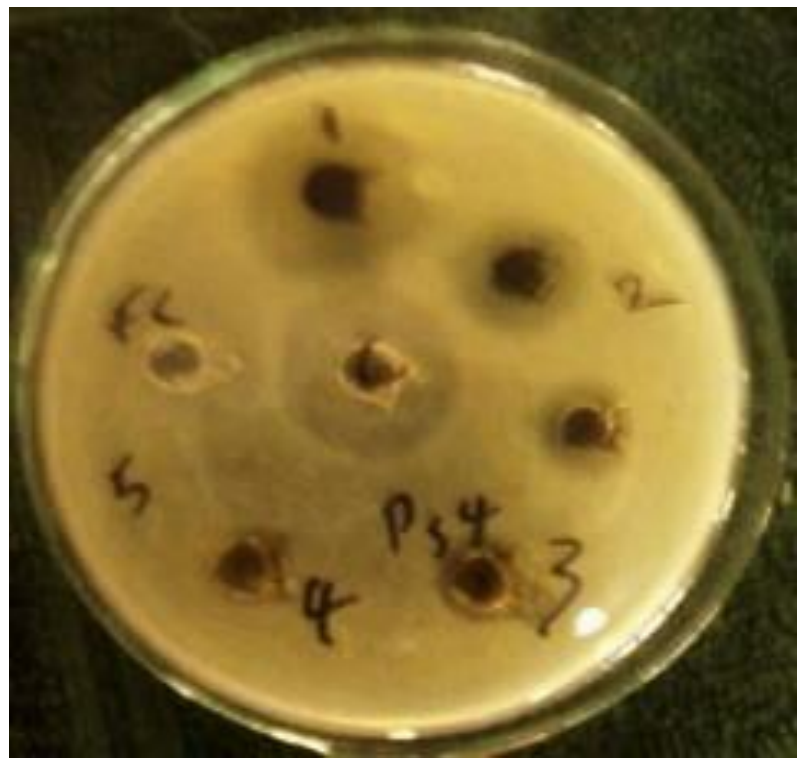

Figure I: Colony formation showing the effect of the ethyl-acetate extract on the Pseudomonas aeruginosa isolates. Keys: $1=200 \mathrm{mg} / \mathrm{ml}$ extract; $2=100 \mathrm{mg} / \mathrm{ml} ; 3=50 \mathrm{mg} / \mathrm{ml} ; 4=25 \mathrm{mg} / \mathrm{ml} ; 5=12.5 \mathrm{mg} / \mathrm{ml} ; \mathrm{Ec}=$ ethyl-acetate (negative control); $\mathrm{C}=$ Gentamycin (Positive control). 

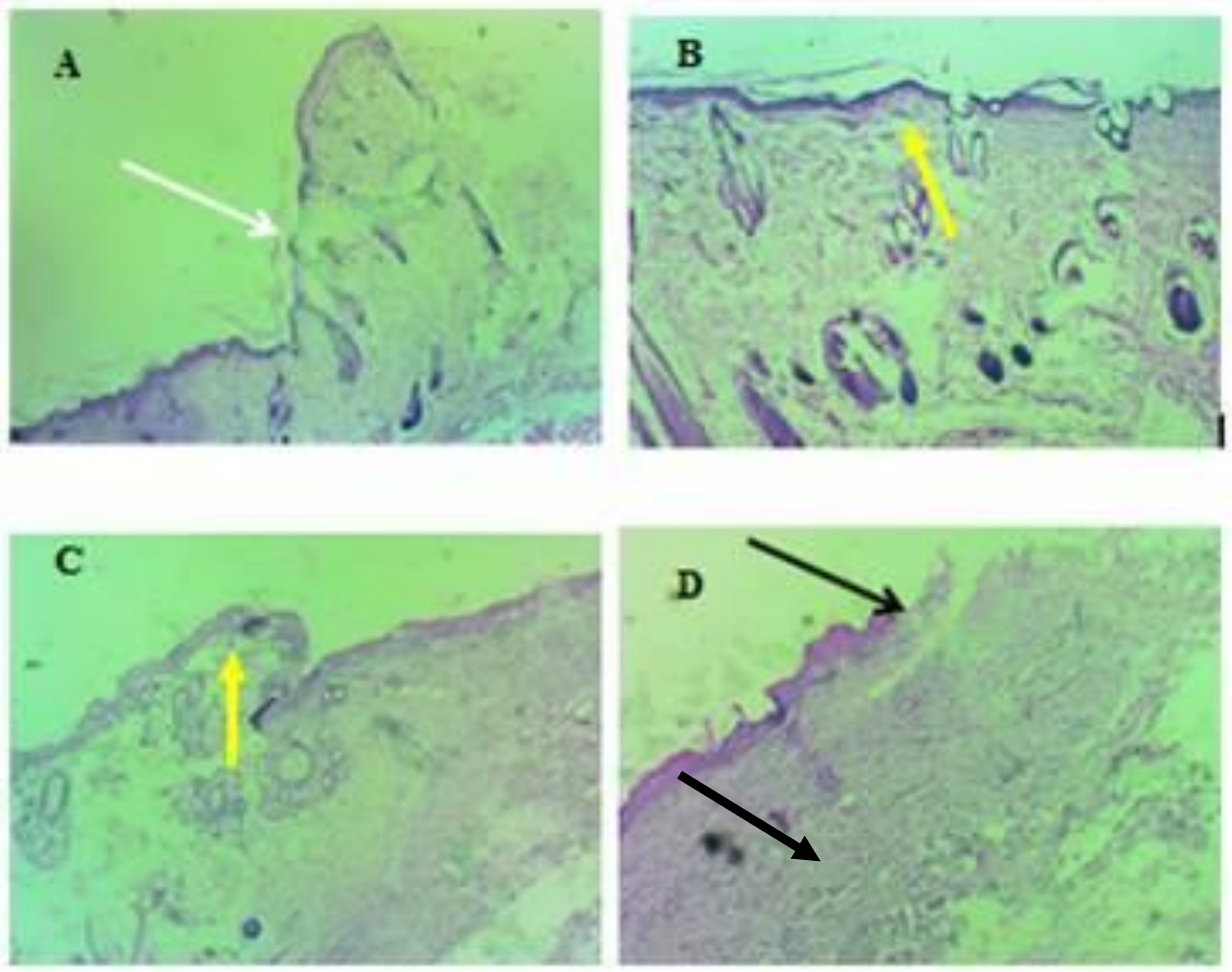

Figure II: Groups A-D: labeled as above showing the skin wound area after treatment. Arrows showing epitheliazation in each group: A gentamicin ointment (white arrow) showing thin, absence of neutrophil, resolution and re-organization of granulation tissue groups B \&C showing thick and complete epitheliazation- 5\% \& 3.25\% Moringa ointment respectively (yellow arrows) D (control) shows incomplete epitheliazation with granulation tissue present in the dermal layer (black arrows).

Table 3: Percentage wound closure rates in the four experimental groups

\section{Percentage Wound Contraction (\%)}

\begin{tabular}{lllll}
\hline Post wounding days & $\begin{array}{l}\text { Gentamicin ointment } \\
\text { (group A) }\end{array}$ & $\begin{array}{l}\text { M. oleifera } 5 \% \mathrm{w} / \mathrm{w} \\
\text { ointment } \\
\text { (group B) }\end{array}$ & $\begin{array}{l}\text { M. oleifera 3.25\% } \\
\text { w/w ointment } \\
\text { (group C) }\end{array}$ & $\begin{array}{l}\text { Ointment base } \\
\text { (group D) }\end{array}$ \\
$\mathbf{3}$ & $9.0 \pm 0.7^{\mathrm{a}}$ & $12.5 \pm 0.5^{\mathrm{a}}$ & $12.0 \pm 0.8^{\mathrm{a}}$ & $11.3 \pm 2.1^{\mathrm{a}}$ \\
$\mathbf{6}$ & $43.0 \pm 0.3^{\mathrm{b}}$ & $36.1 \pm 0.3^{\mathrm{a}}$ & $48.0 \pm 0.2^{\mathrm{b}}$ & $* 39.0 \pm 1.1^{\mathrm{a}}$ \\
$\mathbf{9}$ & $67.0 \pm 0.1^{\mathrm{ab}}$ & $54.0 \pm 0.0^{\mathrm{a}}$ & $59.0 \pm 0.3^{\mathrm{ab}}$ & $* 46.0 \pm 0.5^{\mathrm{a}}$ \\
$\mathbf{1 2}$ & $75.0 \pm 0.1^{\mathrm{ab}}$ & $70.4 \pm 0.1^{\mathrm{a}}$ & $70.0 \pm 0.1^{\mathrm{ab}}$ & $39.0 \pm 0.6^{\mathrm{a}}$ \\
$\mathbf{1 5}$ & $93.0 \pm 0.0^{\mathrm{ab}}$ & $89.0 \pm 0.0^{\mathrm{a}}$ & $100 \pm 0.0^{\mathrm{c}}$ & $37.5 \pm 0.4^{\mathrm{a}}$ \\
\hline
\end{tabular}

Note $^{*}=$ purulent sign, pus and bloody discharge. Similar superscript is not significantly different within each group comparing successive days. 


\section{Discussion}

Developing effective and affordable wound therapy products from plants have been a main focus of ethnopharmacological research. As reported previously (Hukkeri et al. 2006), this study shows clearly that ethyl acetate extract of Moringa oleifera possesses antimicrobial properties in vitro while at lower concentrations. With modifications to the delivery method, the ethylacetate extract stimulates faster wound closure without scarring. This delivery method, although conventional, helps to highlight the possibility of reduced frequency of application of the extract to wounds without the extract losing its efficacy as a wound antimicrobial with a suspected epitheliotrophic property.

Reports by workers have identified the phytochemical components of Moringa oleifera to range from glucosinolates, isothiocyanates, carotenoids, including -carotene or provitamin A (Akhtar and Ahmad, 1995; Bharah et al., 2003; Fahey, 2005) with each having different uses validated from different studies. The potent antimicrobial activity of Moringa oleifera used in from this study further validates the previously reported antimicrobial property of the leaf extracts (Bukar and Loyeyi 2010; Lar et al 2011). The pharmacological activities of most medicinal plants have been found to be directly related to the types of secondary metabolites they contain (Edeoga et al., 2005). The presence of flavonoids, saponins, alkaloids and phlobatannins in the leaves of M. oleifera could account for its antimicrobial activity. The presence of flavonoid and saponins in this study correlates with the report of Bukar and Loyeyi, (2010). Flavonoids and tannins have been found to be effective against a wide array of microorganisms (Tsuchiya et al., 1996), while alkaloids are also known to impair enzymes that microorganisms use in energy production, thereby interfering with the integrity of their cell membrane and structural component synthesis (Babbar et al 2015).

The Staphylococcus aureus isolate was resistant to gentamicin which is a broad spectrum antibiotic but sensitive to the ethyl acetate extract. The inhibitory activity of ethyl acetate extract on all the clinical wound isolates showed its broad spectrum of antimicrobial activity. Ethno-medicinal studies have shown that plants containing natural antimicrobials and active components isolated from plants have provided leads in the development of several drugs currently in use (Rastogi and Mehrotra 2002). The antimicrobial activity of plants is believed to be due to the presence of phytochemicals which they synthesize as self-defense mechanisms against invading pathogens.

Ointment formulations containing ethyl acetate leaf extracts of $M$. oleifera demonstrated significant wound healing activity which was characterized by rapid wound healing and contraction rates and reduced epithelization period. Application of the leaf extract ointment prevented the invasion of the wound site by microorganisms, thus protecting the wound from being infected thereby enhancing rapid wound healing process. This is clearly demonstrated in the purulent signs accompanied with pus and blood from the $6^{\text {th }}$ day in wounds where only the ointment base was applied which were evident signs of infection. Hukkeri et al. (2006) reported similar results about ethyl acetate extract of $M$. oleifera on wound healing.

However, lower concentration of ethyl acetate ointment used $(3.25 \%)$ appears to stimulate wound healing process possibly through increased fibroplasia or mobilization/kinetic effect on cellular component of wound healing. This suspected process appears to be absent at higher concentrations of ethylacetate ointment which may be responsible for delayed wound closure at day 15 post wounding.. This effect could be due to the presence of many concentration dependent metabolite in the ethylacetate ointment formulation which either aids or retards wound healing; hence, further studies to identify fraction of ethylacetate extract which could possibly have a concentration dependent effect on wound healing process in underway. This result, if achieved, could prove a better antibiotic as well as wound healing stimulant as opposed to gentamicin alone which showed lesser wound contraction rates compared to lower concentration of test ointment.

From this study, it can be deduced that M. oleifera leaf possesses a promising compound which when fractionated and applied to wound care, could prove better result than commonly used existing drugs.

Similar results have been reported about aqueous extract of M. oleifera leaves. Rathi et al. (2006) evaluated wound healing property of the on male Swiss albino mice and reported significant increase in wound closure rate, skin breaking strength, granuloma breaking strength, hydroxyproline content, granuloma dry weight and decrease in scar area. Similarly, Hukkeri et al. (2006) investigated antipyretic and wound healing activity from the ethanolic and ethyl acetate extracts of $M$. oleifera leaves and reported that the ethyl acetate extract of dried leaves showed significant wound healing activity on excision, incision and dead space (granuloma) wound models in rats.

As observed from this study, incorporation of the ethyl acetate extract into an ointment preparation improved the delivery of the extract and ensured prolonged contact with the wound area thus maximizing the effect of the extract as well as decreasing application frequency.

Histology of the wounds corroborates well with the measured wound contraction rate as this explains a possible trophic effect of the metabolites of Moringa extract used on epithelial cells as revealed by the thickness and rate of the epidermal covering, granulation tissue resolution, healing evidence by restoration of tissue architecture around the wound site. This possible trophic mechanism of action needs to be validated.

In conclusion, ethyl-acetate extract of Moringa leaf demonstrated antimicrobial action in vitro. It also stimulated faster wound closure rate with absence of scarring with a suspected trophic action on epidermal cells when applied using ointment preparations which ensured prolonged stay at wound site, thereby decreasing frequency of application in vivo. 
Hence, this study corroborates existing literatures and further justifies the traditional use of $M$. oleifera in wound healing when applied as ointment preparation with further studies being carried out on the active compound and the mechanism with which these actions are mediated.

Conflict of Interest: The authors of the work hereby declare no conflict of interest.

\section{References}

1. Adline, J. and Devi, A. (2014). A study on phytochemical screening and antibacterial activity of Moringa oleifera. Int. J. of Res. in App.,Nat. and Soc.Sci.,. 2(5):169-176.

2. Akhtar AH and Ahmad KU. (1995). Antiulcerogenic evaluation of the methanolic extracts of some indigenous medicinal plants of Pakistan in Aspirin-ucerated rats, J. Ethnopharmacol., 46 (1), 1-6.

3. Anwar, F., Latif, S., Ashraf, M. and Gilani, A. H. (2007). Moringa oleifera: A food plant with multiple medicinal uses. Phytotherapy Res. 21(1):17-25.

4. Arulselvan P., Fard M. T., Tan W. S., et al., (2016). "Role of Antioxidants and Natural Products in Inflammation," Oxidative Med. and Cell. Longevity, Article ID 5276130, 15 pages, 2016. doi:10.1155/2016/5276130.

5. Babbar, N., Oberoi, H. S., \& Sandhu, S. K. (2015). Therapeutic and nutraceutical potential of bioactive compounds extracted from fruit residue. Critical Rev. in Food Sci. and Nut., 55(3), 319-337. PMid:24915390. http://dx.doi.org/10.1080/10408398.2011.653734

6. Bharah R, Tabassum J, Azad MRH (2003). Chemomodulatory effect of Moringa oleifera Lam. on hepatic carcinogen metabolizing enzymes, antioxidant parameters and skin papillomagenesis in mice. Asian Pacific J. Cancer Prev. 4: 131- 139

7. Bowler PG, Duerden BI, Armstrong DG. (2001). Wound microbiology and associated Approaches to Wound Management. Clin. Microbio. Rev. 14: 244-269.

8. Bukar, A. and Loyeyi, T. I. (2010). Antimicrobial profile of Moringa oleifera Lam. extracts against some food borne microorganisms. J. of Pure and App. Sci., 3 (1):43-48.

9. Dangi. S. Y., Jolly, C. I. and Narayana, S. (2002). Antihypertensive activity of the total alkaloids from the leaves of Moringa oleifera. Pharm. Biol., (40):144-148.

10. Demidova-Rice TN, Hamblin MR, Herman IM. (2012). Acute and Impaired Wound Healing: Pathophysiology and Current Methods for Drug Delivery, Part 1: Normal and Chronic Wounds: Biology, Causes, and Approaches to Care. Advances in skin \& wound care.; 25(7):304-314. doi:10.1097/01.ASW.0000416006.55218.d0.

11. Edeoga, H.O, Okwu, D.E. and Mbebo, B.O. (2005). Phytochemical constituents of some Nigerian plants. Afr. J. of Biotech. 4: 685-688.

12. Enoch, S. and Leaper, D.J. (2005). Basic science of wound healing. Surgery, 23: 37-42.

13. Fahey, J. W. (2005). Moringa oleifera: A review of the medical evidence for its nutritional, therapeutic, and prophylactic properties. Part 1. Trees Life J., (1):1-15.

14. Filius PM, Gyssens IC. (2002). Impact of increasing antimicrobial resistance on wound management. Am J Clin. Dermatol. 3(1):1-7.

15. Hukkeri, V. I., Nagathan, C. V., Karadi, R. V. and Patil, B. S.. (2006). Antipyretic and wound healing activities of Moringa oleifera Lam in rats. Indian J. Pharmaceut. Sci., (68):124-126.

16. Kumar, B., Vijayakumar, M., Govindarajan, R. and Pushpangadan, P. (2007) Ethnopharmacological approaches to wound healing-exploring medicinal plants of India. J. Ethnopharmacol., (114):103-113.

17. Lar, P. M; Ojile, E. E; Dashe, E. and Oluoma J. N. (2011) antibacterial activity of Moringa oleifera seed extracts on some gram negative bacterial isolates Afr. J. of Nat. Sci., 14, 57 - 62.

18. Murthy S., Gautam M. K., Shalini Goel, Purohit V., Sharma H., and Goel R. K., (2013). "Evaluation of In Vivo Wound Healing Activity of Bacopa monniera on Different Wound Model in Rats," BioMed Res. Internat., vol. 2013, Article ID 972028, 9,. doi:10.1155/2013/972028

19. Okigbo, R.N., Eme, U.E., and Ogbogu, S. (2008). Biodiversity and conservation of medicinal and aromatic plants in Africa. Biotechnol. Mol. Bio. Rev., (3):127-134.

20. Okwu, D.E. and Josiah, C. (2006). Evaluation of the chemical composition of two Nigerian medicinal plants. Afr. J. Biotech, 5(4): 357-361.

21. Pattanayak, S.P. and Sunita, P. (2008). Wound healing, antimicrobial and antioxidant potential of Dendrophthoe falcata (L.f) Ettingsh. J. Ethnopharmacol. (120): 241-247.

22. Pîrvănescu H, Bălăşoiu M, Ciurea ME, Bălăşoiu AT, Mănescu R. (2014). Wound infections with multi-drug resistant bacteria. Chirurgia (Bucur). Jan-Feb;109 (1):73-9.

23. Rastogi, R.P. and Mehrotra, B.N. (2002) Glossary of Indian medicinal plants. National Institute of Science Communication, New Delhi. 20-25

24. Rathi, B. S., Bodhankar, S. L. and Baheti, A. M. (2006). Evaluation of aqueous leaves extract of Moringa oleifera Linn for wound healing in albino rats, Indian J. of Exp. Bio., (44): 898-901.

25. Reddy L., Moradi F., Koch C. (2007). Top-down biases win against focal attention in the fusiform face area. Neuroimage 38, 730-73910.1016/j.neuroimage. 
26. Schultz G, Mozingo D, Romanelli M, Claxton K (2005) Wound healing and TIME: new concepts and scientific applications. Wound Repair Regen 13(4 Suppl): S1-S11

27. Sofowora, A. (1993). Screening Plants for Bioactive agents in: medicinal plants and Traditional medicine in Africa. $2^{\text {nd }}$ Edn. Spectrum Books Ltd, Ibadan, Nigeria. 134-155.

28. Estevão, L. R. M., Medeiros, J. P. D., Simões, R. S., Arantes, R. M. E., Rachid, M. A., Silva, R. M. G. D., Mendonça, F. D. S. \& Evêncio-Neto, J. (2015). Mast cell concentration and skin wound contraction in rats treated with Brazilian pepper essential oil (Schinus terebinthifolius Raddi). Acta cirurgica brasileira, 30(4), 289-295.

29. Srinivasan, D., Nathan, S. and Perumalsamy, O. (2001). Antimicrobial activity of certain Indian medicinal plants used in folkloric medicine. J. of Ethnopharmacolo., (74): 217-220.

30. Strodtbeck, F. Physiology of wound healing in Newborn Infant. Nurs. Rev. 2001 (1): 43-45.

31. Sumitra, M., Manikandana, P. and Suguna, L.(2005). Efficacy of Butea monosperma on dermal wound healing in rats. Int. J. Biochem. Cell Biol. (37):566-573.

32. Tam, J. C. W., Lau, K.M. and Liu, C. L. (2011). The in vivo and ex-vivo diabetic wound healing effects of a 2 herb formula and its mechanisms of action. J. of Ethnopharmacolo., , 134 (3):831-838.

33. Trease, G. E. and Evans, W. C. (2002). Phytochemistry in: Phymacognosy . $15^{\text {th }}$ Edn. Saunders Publishers, London. Pg. 137-149.

34. Tsuchiya, H., Sato, M., Miyazaki, T., Fujiwara, S., Tanigaki, S., Ohyama, M., Tanaka, T. and Linuma, M. A. (1996). Prenylated flavanone from roots of Amorpha fruticosa. J. of Ethnopharmarcolo. (50):27. 